\title{
Comparing geometric parameters of a hydrodynamic cavitation process treating pesticide effluent
}

\author{
Shrikant B. Randhavane ${ }^{\dagger}$ \\ Department of Civil Engineering, SVKM's Institute of Technology, Dhule-424001, India
}

\begin{abstract}
Paper focuses on comparison between two different orifice plate configurations (plate number 1 and plate number 2) used as cavitating device in the hydrodynamic cavitation reactor for improving pollutant removal efficiencies. Effect of four different parameters such as hydraulic characteristics (in terms of range of flow rates, orifice velocities, cavitation number at different inlet pressures); cavitation number (in range of 5.76-0.35 for plate number 1 and 1.20-0.35 for plate number 2); inlet pressure (2-8 bars) and reaction time (0 to $60 \mathrm{~min})$ in terms of chemical oxygen demand (COD) removal and chlorpyrifos degradation has been studied and compared. Optimum inlet pressure of 5 bars exists for degradation of pollutants for both the plates. It is found that geometry of orifice plate plays important role in removal efficiencies of pollutant Results obtained confirmed that orifice plate 1 with configuration of $1.5 \mathrm{~mm} 17$ holes; cavitational number of 1.54 performed better with around $60 \%$ COD and $98 \%$ chlorpyrifos removal as compared to orifice plate 2 having configuration of 2 mm single hole; cavitational number of 0.53 with $40 \%$ COD and $96 \%$ chlorpyrifos in $2 \mathrm{~h}$ duration time.
\end{abstract}

Keywords: Chemical oxygen demand, Chlorpyrifos, Degradation, Efficiency, Hydrodynamic cavitation, Real effluent

\section{Introduction}

Intensive agriculture has resulted into development of the agro-chemical industries [1]. This has resulted into uncontrolled manufacturing of pesticides (factories area), storage (factories and agricultural area) and uses, especially in lower-income countries [2]. There are different types of stages through which pesticide wastes are formed. It includes manufacturing, use and storage, etc. Extreme use leads to contaminate water with high concentrations of pesticides [2]; with number of pollutants being detected in natural water resources [3]. Also, in municipal waste water treatment plants, some products of these hazardous pollutants have been detected [4]. Even if these pollutants are present in very low/less concentrations, they are considered toxic and detrimental [5]. High toxicity and low biodegradability of these products is main concern for the environment [4]. Also they affect aqueous habitats and cause threat to human health [3] and thus their removal from the contaminated water is of high priority [5].

Chlorpyrifos is the common name for the chemical 0,0-diethyl 0-(3,5,6-trichloro-2-pyridinyl)-phosphorothioate. Chlorpyrifos is broad spectrum pesticide, which belongs to organophosphate group of pesticides, and is used world-wide for different applications such as agriculture, pest control, etc. Its wide use has resulted into uncontrolled manufacturing and contamination of environmental matrices. In USA, Dow Chemical Company registered it firstly for use in 1965 [6]. Chlorpyrifos acts against various range of disease causing elements, is used widely in residential and agriculture pest control all around the world. Human exposure to CPF may cause chronic effects such as impaired memory and concentration, headache, confusion, nausea, weakness, etc. [7-10]. Use of chlorpyrifos causes greater health risk when it exceeds acute exposure levels [11]. It persists in nature for relatively long period due to its physicochemical and structural properties, low volatilization and degradation under aerobic conditions. By comparing risks of $\mathrm{CPF}$, using standard risk quotient approach, results indicates that CPF has second or third highest risk quotient to terrestrial species comparing to other insecticides and first or second highest risk quotient to aquatic species [12]. Thus, effluent comprising this pesticide is procured and chosen as model pollutant in this study.

For achieving effective removal of pollutant, ideal treatment method should be qualified/appropriate, should perceive complete mineralization rapidly and should be suitable for small-scale waste
This is an Open Access article distributed under the terms of the Creative Commons Attribution Non-Commercial License (http://creativecommons.org/licenses/by-nc/3.0/) which permits unrestricted non-commercial use, distribution, and reproduction in any medium, provided the original work is properly cited.

Copyright (C) 2019 Korean Society of Environmental Engineers
Received July 9, 2018 Accepted August 7, 2018

${ }^{\dagger}$ Corresponding author

Email: srandhavane@gmail.com

Tel: $+91-8160180980$

ORCID: 0000-0002-7219-3222 
applications [13]. Advanced Oxidation Potential (AOP's) are now-a-days preferred methods in dealing with pesticide degradation [1, 14]. Hydroxyl radicals $\cdot \mathrm{OH}$ are second strongest known oxidant only after Fluorine. Use of AOP is advantageous due to fact that it can be produced with number of possibilities as per the specific requirements.

Hydrodynamic cavitation generates $\bullet \mathrm{OH}$ radicals and involves the phenomenon that accompanies the flow of liquids through the canals of characteristic variables of liquid. It is helpful/ aiding chemical processes, specifically in technology which deals with mortification/degradation of substances which are harmful for environment and human beings [15]. It progresses in the formation, growth and subsequent collapse of micro-bubbles or cavities occurring in great degree of tiny timeframes (milliseconds) with release of large magnitudes of energy [16, 17]. Treatment of water due to cavitation is mainly caused due to mechanisms of mechanical (e.g., generation of turbulence, liquid circulation currents and shear stresses), chemical (generation of active free radicals) and heat effects (generation of local hot spots i.e., condition of very high temperature and pressure locally) [16]. When local pressure falls below the vapor pressure of the fluid, cavities are created [18]. The radicals produced from hydrodynamic cavitation such as $\cdot \mathrm{H}$ and $\cdot \mathrm{OH}$ can react with pollutants in water to promote degradation of pollutants $[19,20]$. Potential applications of use of hydrodynamic cavitation in field of Chemical Processes [18, 21-23]; wastewater treatment [24-27], etc. are documented. In dealing with $\mathrm{HC}$ process treatment, different geometrical parameters and configurations play an important role in attaining significant results. Present paper focuses on this aspect and comparing two different orifice plate configurations in degradation of chemical oxygen demand (COD) and chlorpyrifos pesticide from pesticide manufacturing effluent. This work is novel in terms of configuration and initial waste water characteristics used and further extension of our earlier works $[12,28]$ regarding use of HC in degradation of chlorpyrifos pesticide and COD from real effluent. The research was carried out at pilot plant setup at Common Effluent Treatment Plant (CETP), Vapi, Gujarat State, India from January 2016 to December 2017.

\section{Materials and Methods}

Real effluent is procured from one of pesticide manufacturing premises near Surat, India. (Source not reveled due to confidential issues). HPLC analysis was done to find the chlorpyrifos content after the treatment at any specific time. HPLC instrument used consists of HPLC pump [Serial dual plunger, micro volume (10 $\mu \mathrm{L}$ on primary side, $5 \mu \mathrm{L}$ on secondary)] with $\mathrm{UV}$ detector having wavelength range between 190-600 $\mathrm{nm}$ and Lichrospher $(5 \mu \mathrm{m})$ analytical column. Acetonitrile and water were used as mobile phase (85:15) with a flow rate of $1 \mathrm{~mL} / \mathrm{min}$ and the detection was effected at a wavelength of $230 \mathrm{~nm}$. All experimental samples were analyzed with the same HPLC parameters. Along with this, COD concentration was analyzed with standard operating procedure. All the experiments were conducted for three replicates to ensure any error and change in results.

Following Fig. 1 shows schematic illustration of the ex- perimental setup used for hydrodynamic cavitation. The details of setup consists of orifice plates as cavitating device as shown in Fig. 2. System consists of closed loop consisting of holding tank (20 liters capacity volume), centrifugal pump (2,900 rpm, $1.1 \mathrm{~kW}$ ), control valves, orifice plate, flanges to place orifice plate, pressure gauges to measure upstream and downstream pressure and cooling jacket arrangement to circulate cold water around holding tank. Suction side of pump is connected to bottom of holding tank and discharge branches into two lines namely main line and bypass line having valves $V_{2}$ and $V_{3}$, respectively placed at appropriate places. By pass line is provided to adjust liquid flow through main line. Care is taken that both main line and bypass line terminate well below liquid surface in feed tank. This is done to avoid the possible induction of air into the liquid due to plunging jet. By pass valve was kept fully open till pump attains maximum speed. Pressure gauges have been provided at appropriate places (one before cavitating device and other after) which gives inlet pressure and fully recovered downstream pressure.

Orifice plates as shown in Fig. 2 were used in this study and compared for their chlorpyrifos pesticide removal efficiencies and COD reduction from real pesticide manufacturing effluent. Plate 1 consists of 17 holes each of $1.5 \mathrm{~mm}$ diameter. Plate 2 represents 1 hole with $2 \mathrm{~mm}$ diameter. Ratio of total area of opening to cross-sectional area of pipe $\left(\beta_{0}\right)$ is 0.061 and 0.006 for plates 1 and 2, respectively.

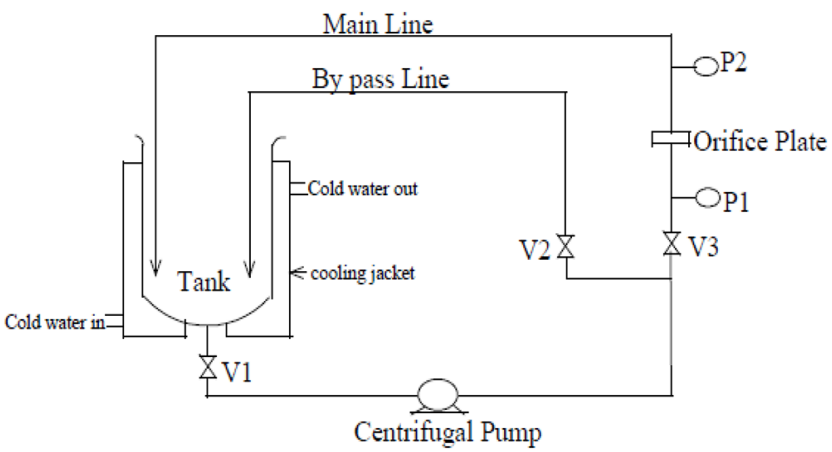

P1,P2 - Pressure Gauges

V1,V2,V3 - Control Valves

Fig. 1. Experimental setup for hydrodynamic cavitation reactor.

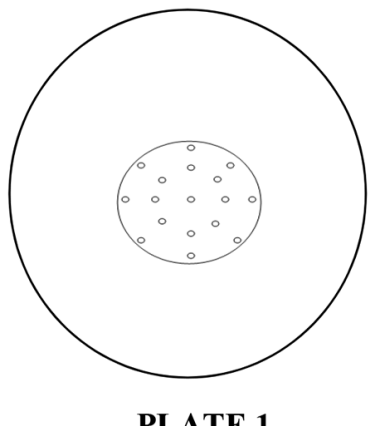

PLATE 1

$1.5 \mathrm{~mm}$ multiple hole

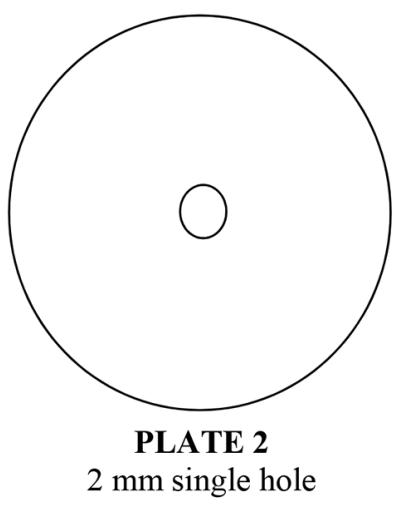

$2 \mathrm{~mm}$ single hole
Fig. 2. Orifice plate configurations used as cavitating device. 
Table 1. Flow Characteristics for Plates

\begin{tabular}{|c|c|c|c|c|c|c|}
\hline \multicolumn{4}{|c|}{ Plate 1} & \multicolumn{3}{|c|}{ Plate 2} \\
\hline $\begin{array}{l}\text { Inlet pressure } \\
\text { (Bars) }\end{array}$ & $\begin{array}{c}\text { Mainline flow rate } \\
\text { (lit/s) }\end{array}$ & $\begin{array}{l}\text { Orifice velocity, } \\
\mathrm{V}_{\mathbf{0}} \\
(\mathrm{m} / \mathrm{s})\end{array}$ & $\begin{array}{c}\text { Cavitational } \\
\text { number, } \\
\mathrm{C}_{\mathrm{v}}\end{array}$ & $\begin{array}{c}\text { Mainline flow rate } \\
\text { (lit/s) }\end{array}$ & $\begin{array}{l}\text { Orifice velocity, } \\
\qquad V_{0} \\
(\mathrm{~m} / \mathrm{s})\end{array}$ & $\begin{array}{c}\text { Cavitational } \\
\text { number, } \\
\mathrm{C}_{\mathrm{v}}\end{array}$ \\
\hline 2 & 0.172 & 5.74 & 5.76 & 0.0398 & 12.61 & 1.20 \\
\hline 3 & 0.22 & 7.4 & 3.47 & 0.0483 & 15.41 & 0.8 \\
\hline 4 & 0.285 & 9.52 & 2.09 & 0.0540 & 17.21 & 0.65 \\
\hline 5 & 0.33 & 11.1 & 1.54 & 0.0596 & 19.0 & 0.53 \\
\hline 6 & 0.454 & 15.15 & 0.82 & 0.0636 & 20.28 & 0.46 \\
\hline 7 & 0.53 & 17.83 & 0.57 & 0.0686 & 21.84 & 0.40 \\
\hline 8 & 0.750 & 25 & 0.35 & 0.0737 & 23.47 & 0.35 \\
\hline
\end{tabular}

\section{Results and Discussion}

\subsection{Hydraulic Characteristics of Orifice Plates}

Inlet pressure $\mathrm{P}_{1}$ is adjusted and flow is regulated by operating valve $\mathrm{V}_{2}$ in by-pass line. This results into increase in flow (Q) through main line. It was recorded flow rate increases with inlet pressure by gradually closing by-pass valve $\left(\mathrm{V}_{2}\right)$. Details of flow characteristics for plate 1 and plate 2 are given in Table 1 .

Flow in main line is classified by cavitational number, with consideration of flow conditions in downstream side of cavitating device. Cavitational number is a dimensionless number and given as in Eq. (1).

$$
C_{v}=\frac{P_{2}-P_{v}}{0.5 \rho V^{2}}
$$

Where, $P_{2}$ is fully recovered downstream pressure, $P_{V}$ is vapour pressure of the liquid and $V$ is the velocity through orifice holes.

\subsubsection{Hydraulics characteristics and cavitational number compar- ison of orifice plates}

As per [29] each flow can be attributed by a cavitation number, irrespective of cavitating or not. Its value depends on the geometry, fluid, fluid temperature and the velocity of the flow. It is observed that at each studied inlet pressure there is some cavitation number calculated. Also, comments as per earlier literature stating that cavities are generated ideally at conditions $\mathrm{C}_{\mathrm{v}}<1$ does not hold good as compared with study of [29]. Regarding study of cavitation number and inlet pressure; it is observed that, for plate 1, cavitation number reduces from 5.76 to 0.35 and from 1.20 to 0.35 with increase in inlet pressure from 2 to 8 bars for plate 1 and plate 2 , respectively. Similar results regarding reduction of cavitation number with increase in inlet pressure from 1-3 bars is also observed by [30]. Fig. 3(a) and (b) elaborates effect of cavitation number in reduction of pollutants from real effluent for plates 1 and 2, respectively. It is observed that pollutant removal increases with reduction in cavitation number up to certain cavitation number and then decreases for both orifice plates. In present case, with reduction in cavitation number from 5.76 to 1.54 and 1.20 to 0.53 for orifice plates 1 and 2, respectively, more number of cavities are generated and they collapse violently generating highly reactive $\mathrm{OH} \bullet$ radicals. This results in increase in higher percent degradation efficiency of the reactor. With further reduction in cavitation number, reactor efficacy in removal of pollutant is decreased as seen in Fig. 7(a) and (b). This is due to fact that, velocity of solution is increased considerably, which results in carriage of bubbles in downstream side with minimum collision or collapse. As collision or collapse is reduced, it generates very less amount of $\mathrm{OH} \bullet$ radicals and forms chocked flow conditions.
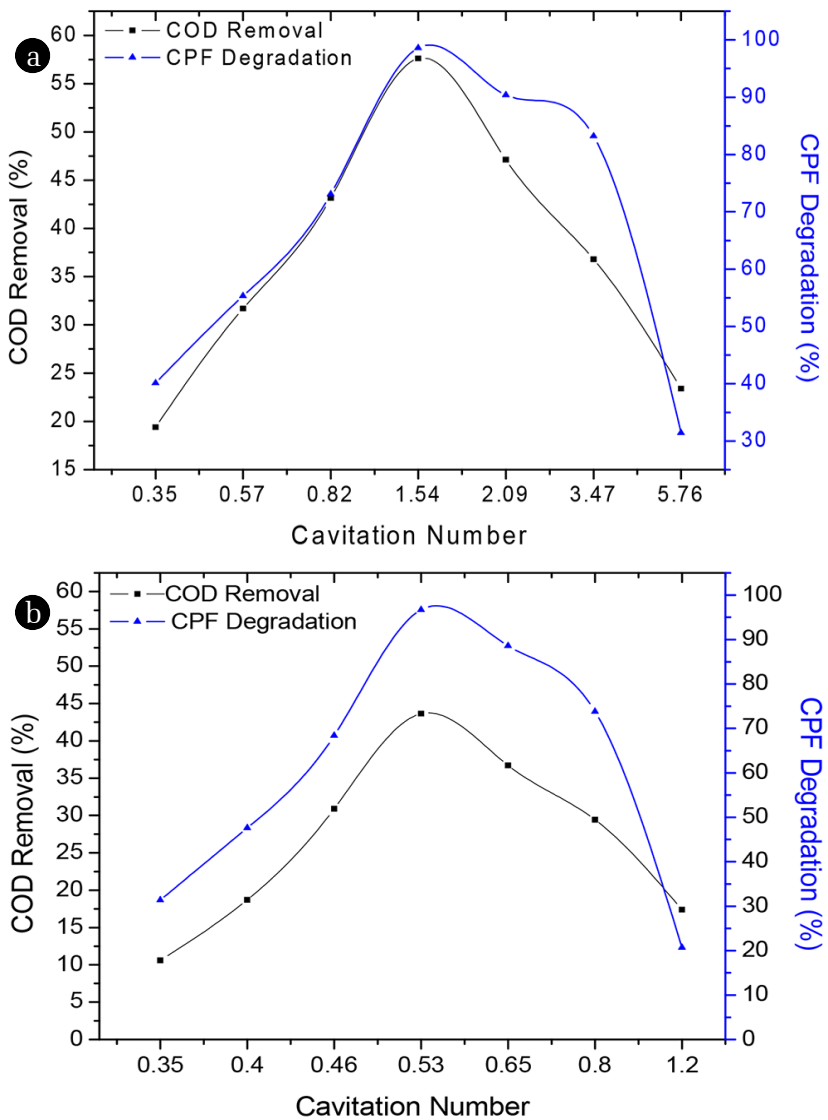

Fig. 3. Effect of cavitation number on removal of pollutant: a) plate 1 , b) plate 2 . 
Thus, in present study, cavitation numbers of 1.54 and 0.53 for plates 1 and 2 respectively are obtained. Particularly, in case of plate 1, cavitation number 1.54 obtained confirms to the comment by [29], that value depends on the geometry, fluid, fluid temperature and the velocity of the flow.

\subsection{Inlet Pressure Effect on Degradation of Chlorpyrifos and $\mathrm{COD}$}

As discussed in Fig. 4, when inlet pressure increases, rate of flow in main line too increases. This increase in flow rate varies for both plates depending upon configuration of each plate. For same inlet pressures of 2 to 8 bars, solution/ liquid experiences different cavitational experience due to variation in flow rates as illustrated in Table 1. As seen from Table 1, with increase in inlet pressure, flow rate in main line increases, along with increase in Orifice velocity. This increase in velocity corresponds to decrease in cavitation number. Determination in optimum inlet pressure is essential in gaining maximum benefit from the reactor. From Fig. 4 it was observed that degradation of chlorpyrifos and COD increase with increase in inlet pressure from 2 bars to 5 bars for both the plates at a fixed time interval of $2 \mathrm{~h}$. After this, the degradation efficiency tends to fall or reduce with further increase in inlet pressure. This is due to phenomenon called super cavitation; in which the bubbles generated in hydrodynamic cavitation reactor does not get explode and forms vapour cloud in the line. Thus, in present case, inlet pressure of 5 bars exists for both plate configurations and degradation of CPF. Similar observations of optimum inlet pressure are seen in treatment of brewery spent wastewater [31]; degradation of organic wastewater [32]; decolorization of azo dyes [33].

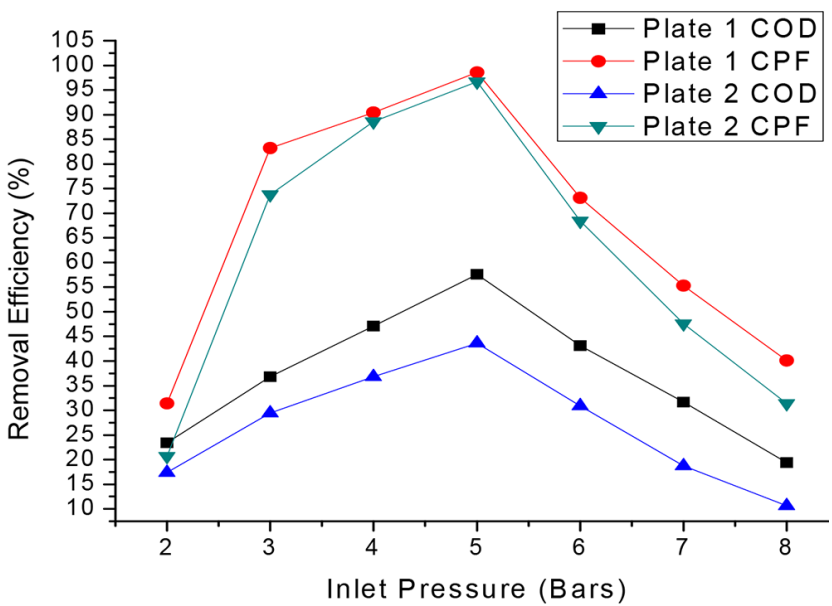

Fig. 4. Effect of inlet pressure on degradation of COD and CPF.

\subsection{Effect of Reaction Time}

With closed loop, the solution experiences more cavitational experience with respect to time. It is seen that degradation efficiencies increases with reaction time. Fig. 5 elaborates effect of reaction time in degradation of CPF and COD for both the studied orifice plates for $1 \mathrm{~h}$ reaction period. Comparing both the orifice plates for their efficiencies, it is seen plate 1 gives better efficiency, due to more cavitational interaction and violent collapse of cavities, which produce better Hydroxyl Radicals. This excess hydroxyl helps in removing the contaminants in form of COD and CPF removal. It is observed that orifice plate 1 yielded more COD and $\mathrm{CPF}$ removal of $58 \%$ and $88 \%$, respectively at end of $1 \mathrm{~h}$. It is caused by enhanced collapse of cavities due to more holes with smaller diameter of holes in plate 1. This high shear zone is evenly distributed in cross section of pipe. It is reported that concentration of alachor decreased exponentially with the reaction time from 0 to $100 \mathrm{~min}$ [19]. Rate of Iodine liberation was function of time as reported by [34]. Also, reaction time is important aspect in improved biogas production with help of induced deflocculatio [35].

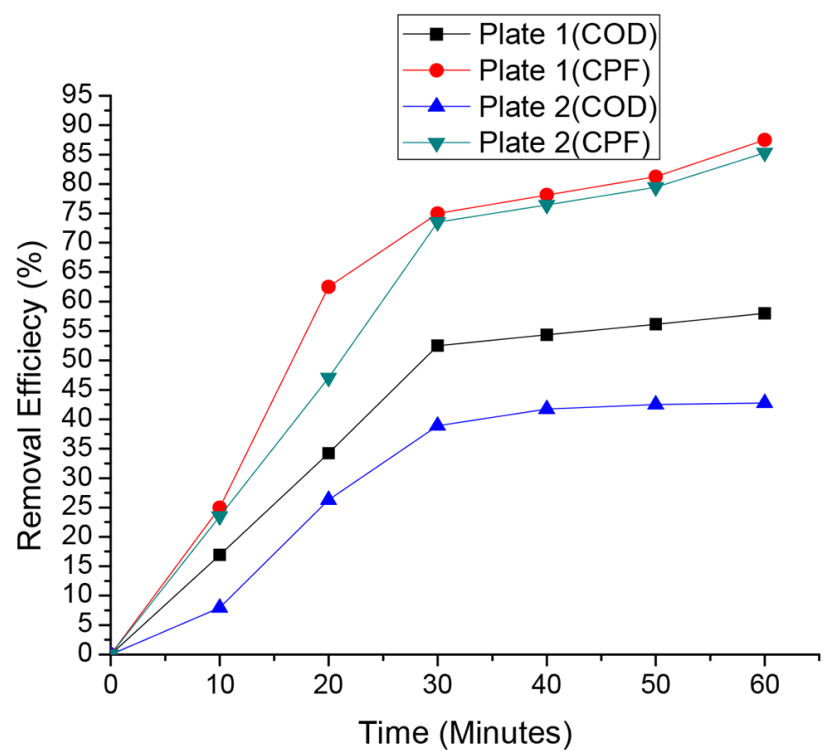

Fig. 5. Effect of reaction time on degradation efficiency.

Similarly, percent decrease of pollutants per circulations/pass through cavitating zone is as shown in Fig. 6 and Fig. 7 for plate number 1 and 2, respectively.

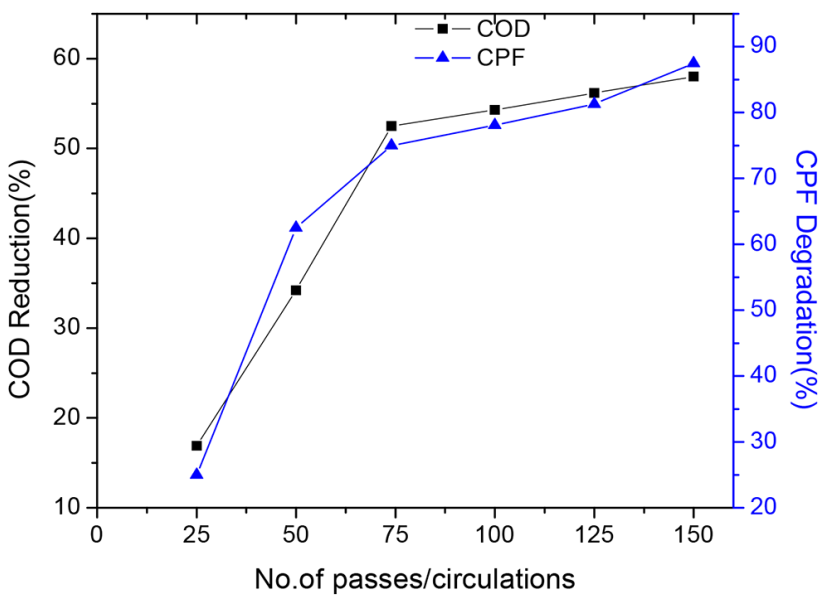

Fig. 6. Comparison of percent reduction of pollutant per circulation for plate 1 


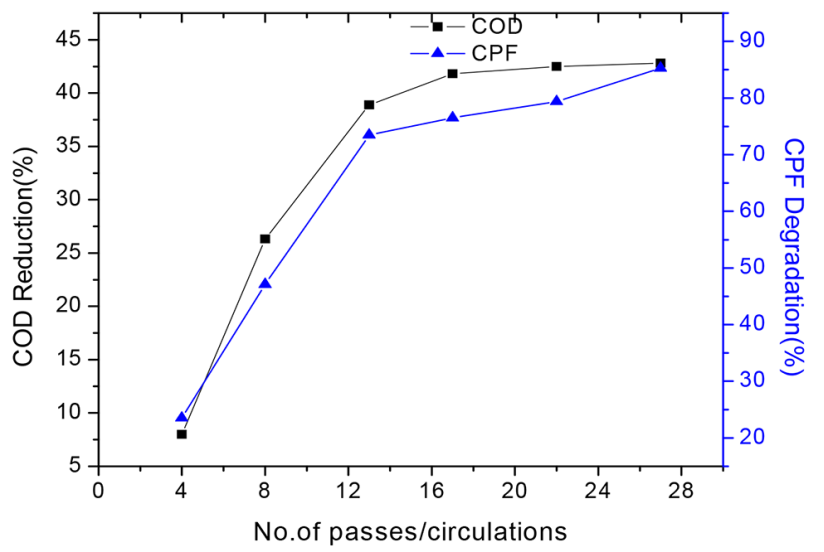

Fig. 7. Comparison of percent reduction of pollutant per circulation for plate 2 .

\section{Conclusions}

Present work states that recalcitrant compound chlorpyrifos, found in effluent that is generated from pesticide manufacturing can be treated/ degraded with hydrodynamic cavitation approach. Potential application for its use in field/ site conditions is proved as the reactor gave more than $42 \%$ organic contaminant reduction in form of COD, along with harmful recalcitrant compound removal of minimum $90 \%$ throughout. By comparing different cavitating devices, it is found that orifice plate 1 with configuration of multiple holes with small diameter yielded maximum efficiency as compared to other plate in all parameters studied. Similar results were found in production of methyl ester [30]; computational study of different venturi and orifices [36]. The reason behind this is enhanced cavitational activity occurred due to more shear force witnessed by liquid generating large number of small cavities and its subsequent collapse. Rate of degradation increases with increase in inlet pressure up to optimum pressure of 5 bars for both orifice plates. Study regarding effect of cavitation number suggests that optimum cavitation number should be established, based upon the configurations of orifice plates. Study reveals that cavitation numbers of 1.54 and 0.53 are obtained at inlet pressures of 5 bars for plate 1 and plate 2, respectively. Effect of reaction time suggests that with increase in time, solution witness cavitation activity for number of time and thus help in pollutant degradation. In future, multiple hole orifice plates having different combinations of number, diameter and shape of holes can be constructed. Such types of arrangements can be helpful to achieve different intensities of cavitation, which will be helpful for numerous applications. Also, reactors present tremendous flexibility in terms of the operating (control of inlet pressure, inlet flow rate and temperature) and geometric conditions (different arrangements of holes on the orifice plates). Depending on the type of application and requirements, geometry and operating conditions can be selected in the hydrodynamic cavitation reactor to maximize the cavitational effects at minimum possible energy consumption.

\section{Acknowledgments}

The corresponding author would like to thank the Management and office bearers of SVKM's Institute of Technology, Dhule for all their support and constant motivation. The author is also thankful to 'CETP' office bearers and 'Center of Excellence' (A division of Vapi Green Enviro Limited, Vapi Industrial Area, Gujarat, India) for their Technical Support, resources and Testing Facility.

\section{References}

1. Oller I, Gernjak W, Maldonado MI, Pérez-Estrada LA, Sánchez-Pérez JA, Malato S. Solar photocatalytic degradation of some hazardous water-soluble pesticides at pilot-plant scale. J. Hazard. Mater. 2006;138:507-517.

2. Taha SM, Amer ME, Elmarsafy AE, Elkady MY. Adsorption of 15 different pesticides on untreated and phosphoric acid treated biochar and charcoal from water. J. Environ. Chem. Eng. 2014;2:2013-2025.

3. Hasan Z, Jhung SH. Removal of hazardous organics from water using metal-organic frameworks (MOFs): Plausible mechanisms for selective adsorptions. J. Hazard. Mater. 2015;283: 329-339.

4. Diaz E, Mohedano AF, Casas JA, Calvo L, Gilarranz MA, Rodriguez JJ. Deactivation of a Pd/AC catalyst in the hydrodechlorination of chlorinated herbicides. Catal. Today 2015;241:86-91.

5. Babuponnusami A, Muthukumar K. A review on Fenton and improvements to the Fenton process for wastewater treatment. J. Environ. Chem. Eng. 2014;2:557-572.

6. John EM, Shaike JM. Chlorpyrifos: Pollution and remediation. Environ. Chem. Lett. 2015;13:269-291.

7. Agudelo RM, Peñuela G, Aguirre NJ, Morató J, Jaramillo ML. Simultaneous removal of chlorpyrifos and dissolved organic carbon using horizontal sub-surface flow pilot wetlands. Ecol. Eng. 2010;36:1401-1408.

8. Bhagobaty RK, Joshi SR, Malik A, et al. Microbial degradation of organophosphorous pesticide: Chlorpyrifos (mini-review). 2006;4:1-6.

9. Farhan M, Khan AU, Wahid A, Ahmad M, Ahmad F. Biodegradation of chlorpyrifos using indigenous Pseudomonas sp. isolated from industrial drain. Pakistan J. Nutr. 2012;11: 1183-1189.

10. George N, Chauhan PS, Sondhi S, Saini S, Puri N. Biodegradation and analytical methods for detection of organophosphorous pesticide: Chlorpyrifos. Int. J. Pure Appl. Sci. Technol. 2014;20:79-94.

11. Phung DT, Connell D, Miller G, et al. Biological monitoring of chlorpyrifos exposure to rice farmers in Vietnam. Chemosphere 2012;87:294-300.

12. Randhavane SB, Khambete AK. Hydrodynamic cavitation: An approach to degrade Chlorpyrifos pesticide from real effluent. KSCE J. Civil Eng. 2018;22:2219-2225. 
13. Kukurina O, Elemesova Z, Syskina A. Mineralization of organophosphorous pesticides by electro-generated oxidants. Procedia Chem. 2014;10:209-216.

14. Badellino C, Rodrigues CA, Bertazzoli R. Oxidation of pesticides by in situ electrogenerated hydrogen peroxide: Study for the degradation of 2,4-dichlorophenoxyacetic acid. $J$. Hazard. Mater. 2006;137:856-864.

15. Ozonek J, Lenik K. Effect of different design features of the reactor on hydrodynamic cavitation process. Arch. Mater. Sci. Eng. 2011;52:112-117.

16. Gogate PR, Mededovic-Thagard S, McGuire D, Chapas G, Blackmon J, Cathey R. Hybrid reactor based on combined cavitation and ozonation: From concept to practical reality. Ultrason. Sonochem. 2014;21:590-598.

17. Rajoriya S, Carpenter J, Saharan VK, Pandit AB. Hydrodynamic cavitation: An advanced oxidation process for the degradation of bio-refractory pollutants. Rev. Chem. Eng. 2016;32:379-411.

18. Chuah LF, Klemeš JJ, Yusup S, Bokhari A, Akbar MM, Chong ZK. Kinetic studies on waste cooking oil into biodiesel via hydrodynamic cavitation. J. Clean. Prod. 2017;146:47-56.

19. Wang X, Zhang Y. Degradation of alachlor in aqueous solution by using hydrodynamic cavitation. J. Hazard. Mater. 2009;161: 202-207.

20. Barik AJ, Gogate PR. Degradation of 4-chloro 2-aminophenol using combined strategies based on ultrasound, photolysis and ozone. Ultrason. Sonochem. 2016;28:90-99.

21. Ghayal D, Pandit AB, Rathod VK. Optimization of biodiesel production in a hydrodynamic cavitation reactor using used frying oil. Ultrason. Sonochem. 2013;20:322-328.

22. Maddikeri GL, Gogate PR, Pandit AB. Intensified synthesis of biodiesel using hydrodynamic cavitation reactors based on the interesterification of waste cooking oil. Fuel 2014;137: 285-292.

23. Prajapat AL, Gogate PR. Intensification of depolymerization of aqueous guar gum using hydrodynamic cavitation. Chem. Eng. Process. Process Intensif. 2015;93:1-9.

24. Rajoriya S, Bargole S, Saharan VK. Degradation of a cationic dye (Rhodamine 6G) using hydrodynamic cavitation coupled with other oxidative agents: Reaction mechanism and pathway. Ultrason. Sonochem. 2017;34:183-194.

25. Capocelli M, Prisciandaro M, Lancia A, Musmarra D. Hydrodynamic cavitation of p-nitrophenol: A theoretical and experimental insight. Chem. Eng. J. 2014;254:1-8.

26. Gogate PR, Patil PN. Combined treatment technology based on synergism between hydrodynamic cavitation and advanced oxidation processes. Ultrason. Sonochem. 2015;25:60-69.

27. Thanekar P, Panda M, Gogate PR. Degradation of carbamazepine using hydrodynamic cavitation combined with advanced oxidation processes. Ultrason. Sonochem. 2018;40:567-576.

28. Randhavane SB, Khambete AK. Harnessing hydroxyl radicals generated by hydrodynamic cavitation reactor in simultaneous removal of chlorpyrifos pesticide and COD from aqueous solution. Desalin. Water Treat. 2017;82:346-354.

29. Šarc A, Stepišnik-perdih T, Petkovšek M, Dular M. The issue of cavitation number value in studies of water treatment by hydrodynamic cavitation. Ultrason. Sonochem. 2016;34:51-59.

30. Chuah LF, Yusup S, Abd Aziz AR, Bokhari A, Abdullah MZ. Cleaner production of methyl ester using waste cooking oil derived from palm olein using a hydrodynamic cavitation reactor. J. Clean. Prod. 2016;112:4505-4514.

31. Montusiewicz A, Pasieczna-Patkowska S, Lebiocka M, Szaja A, Szymańska-Chargot M. Hydrodynamic cavitation of brewery spent grain diluted by wastewater. Chem. Eng. J. 2017;313:946-956

32. Yi C, Lu Q, Wang Y, Wang Y, Yang B. Degradation of organic wastewater by hydrodynamic cavitation combined with acoustic cavitation. Ultrason. Sonochem. 2018;43:156-165.

33. Cai M, Su J, Zhu Y, et al. Decolorization of azo dyes Orange G using hydrodynamic cavitation coupled with heterogeneous Fenton process. Ultrason. Sonochem. 2015;28:302-310.

34. Suslick KS, Mdleleni MM, Ries JT. Chemistry induced by hydrodynamic cavitation. J. Am. Chem. Soc. 1997;119:9303-9304.

35. Chand R, Bremner DH, Namkung KC, Collier PJ, Gogate PR. Water disinfection using the novel approach of ozone and a liquid whistle reactor. Biochem. Eng. J. 2007;35:357-364.

36. Kuldeep, Saharan VK. Computational study of different venturi and orifice type hydrodynamic cavitating devices. J. Hydrodyn. Ser. B. 2016;28:293-305. 